\title{
Nasopharyngeal fiberendoscopy in children: a survey of current Italian pediatric otolaryngological practices
}

\author{
Sara Torretta ${ }^{1 *}$, Paola Marchisio ${ }^{2}$, Giovanni Succo $^{3}$, Pasquale Capaccio $^{1}$ and Lorenzo Pignataro ${ }^{1}$
}

\begin{abstract}
Background: Nasopharyngeal fiberendoscopy (NFE) is the gold standard diagnostic procedure for adenoidal disease, but there is no consensus concerning the optimal technical approach. The aim of this study was to investigate the attitudes of Italian otolaryngologists towards diagnostic NFE in children, and the most widely used methods.

Methods: Nine hundred randomly selected members of the two largest Italian otolaryngological scientific societies were e-mailed an anonymous web-based questionnaire containing 29 multiple-choice items regarding their opinions about, and use of NFE in children.

Results: Questionnaires were returned by 764 clinicians (84.9\%). About $75 \%$ declared they used NFE, but $35 \%$ said they preferred alternative diagnostic methods. Most of the respondents considered NFE safe, but more than $80 \%$ judged it to be poorly or only fairly well tolerated. Almost all declared that they generally use flexible, small-diameter instruments, with the patient seated on a chair or a parent's lap; $65 \%$ use gentle restraining methods. Fewer than $50 \%$ reported using a standardised hypertrophy grading system.

Conclusion: Italian otolaryngologists have a generally positive attitude towards using NFE in children. However, some have reservations, and there was no unanimous agreement concerning how it should be done. Given the medical advantages of NFE, it is essential to clarify the many still controversial aspects of the procedure by means of comparative studies and educational programmes.
\end{abstract}

Keywords: Endoscopy, Nasopharynx, Children, Adenoids, Otolaryngology

\section{Background}

Nasal obstruction due to recurrent or chronic adenoidrelated nasopharyngeal and middle ear infections is frequent in children [1], and often requires an otolaryngological examination in order to assess whether the size of the adenoids and their possible lateral extension are reducing the patency of the ostium of the Eustachian tube, and evaluate the need for surgical treatment.

This can be done by means of nasopharyngeal fiberendoscopy (NFE), a mirror examination with posterior rhinoscopy, a lateral neck roentgenogram, or a standardised clinical questionnaire [2-4]. However, NFE is the gold standard for assessing the volume and surface of the

\footnotetext{
* Correspondence: sara.torretta@gmail.com

'Otolaryngology Unit, Department of Clinical Sciences and Community Health, University of Milan, Fondazione IRCCS Ca' Granda Ospedale Maggiore Policlinico, Via F. Sforza 35, 20122 Milan, Italy

Full list of author information is available at the end of the article
}

adenoids in children with suspected adenoidal disease [5-7] because it is minimally invasive and repeatable, does not expose patients to harmful ionising radiation, and allows direct inspection of the nasopharynx with complete visualisation of the adenoids, thus making it possible to grade hypertrophy and investigate possible choanal or ostial obstruction [5]. It is also a useful means of dynamically evaluating the entire nasal district, including the ostiomeatal complex and sphenoethmoidal recess, and investigating velopharyngeal closure during speech. This makes it possible to identify or exclude any concomitant nasal or rhinosinusal processes, including allergic rhinitis, nasal polyposis, chronic rhinosinusitis, choanal atresia or velar insufficiency, and allows precise surgical stratification in the case that medical treatment fails. 
NFE should therefore be considered a first-level procedure in every otolaryngological facility that has pediatric patients [8]. However, some clinicians are still reluctant because it is not always easy to carry out in the case of younger children and, furthermore, there is no consensus concerning how it should be performed (particularly in relation to the type of instruments to be used) or the most appropriate technical approach to children of different ages or with different diseases. Consequently, it is not clear how, or how extensively NFE is used in everyday practice, particularly in the case of younger children.

The main aim of this study was to evaluate the attitudes of Italian otolaryngologists towards using NFE to diagnose adenoidal diseases in children, and verify the methods actually used in routine clinical practice.

\section{Methods}

\section{Study design}

This cross-sectional survey of the pediatric use of NFE by a representative sample of otolaryngologists belonging to the Italian Society of Otolaryngology and Head and Neck Surgery (SIOeChCF) and the Italian Society of Pediatric Otolaryngology (SIOP) was carried out between September 2012 and May 2013. The study was approved by our local ethics committee of University of Milan.

\section{Study population}

An anonymous questionnaire asking about opinions and practices relating to the pediatric use of NFE was sent to 900 Italian otolaryngologists whose e-mail addresses were selected by means of a computer-based randomisation list.

\section{Questionnaire design and administration}

The web-based questionnaire, which was anonymous but coded in order to be able to identify non-responders and ensure the elimination of multiple responses, was conceived by the first author (ST) and drawn up in collaboration with the co-authors before being pilot tested on a sample of 20 otolaryngologists in Milan, Italy. It required about $10 \mathrm{~min}$ to complete and guided the respondents through multiple-choice items divided into two main sections: one concerning their personal and demographic data (including gender, and the years of birth, graduation and specialisation); the other consisted of 29 items concerning their attitudes towards using diagnostic NFE in children, and the methods they use in routine clinical practice.

\section{Statistical analysis}

The data were descriptively analysed to assess the prevalence and distribution of all the variables. The continuous variables were expressed as mean values and standard deviations (SDs), and the categorical variables as absolute numbers and percentages. The categorical variables were dichotomously analysed at multiple levels. The KruskalWallis equality-of-populations rank test and Fisher's exact test were used to determine whether attitudes toward NFE and the way it was carried out were related to the demographic data. After adjusting for the main confounders, univariate and multivariate logistic regression models were used to compute odds ratios (ORs) and standard errors (SEs) and $95 \%$ confidence intervals (95\% CIs) in order to measure the strength of the associations. Statistical significance was set at $p=0.05$. The data were analysed using STATA 10.0 software (StataCorp, College Station, TX).

\section{Results}

Questionnaires were returned by 764 of the 900 otolaryngologists (84.9\%), most of whom were males (589; $77.1 \%)$, aged $>50$ years $(395 ; 51.7 \%)$, worked in northern Italy (455; $59.5 \%)$, and practised in a hospital setting (397; $52.0 \%$ ) (Table 1 ).

Table 2 shows their attitudes towards NFE. About $75 \%$ of the respondents declared that they used NFE, but $35 \%$ said they still preferred alternative diagnostic

Table 1 Demographic characteristics of the otolaryngologists returning completed questionnaires

\begin{tabular}{|c|c|c|}
\hline Demographic characteristics & No. of respondents & Percent \\
\hline Total number & 764 & \\
\hline Males & 589 & 77.1 \\
\hline \multicolumn{3}{|l|}{ Age, years } \\
\hline$\geq 50$ & 395 & 51.7 \\
\hline $36-50$ & 322 & 42.1 \\
\hline$\leq 35$ & 47 & 6.2 \\
\hline $\begin{array}{l}\text { No. of otolaryngologists working } \\
\text { in Northern Italy }\end{array}$ & 455 & 59.5 \\
\hline \multicolumn{3}{|l|}{ Work setting } \\
\hline Hospital & 397 & 52.0 \\
\hline University & 70 & 9.2 \\
\hline Private practice & 297 & 38.8 \\
\hline \multicolumn{3}{|l|}{ No. of years since graduation } \\
\hline$\geq 31$ & 159 & 20.8 \\
\hline $20-30$ & 314 & 41.1 \\
\hline $11-19$ & 164 & 21.5 \\
\hline$\leq 10$ & 127 & 16.6 \\
\hline \multicolumn{3}{|l|}{$\begin{array}{l}\text { No. of years since specialising } \\
\text { in otolaryngology }\end{array}$} \\
\hline$\geq 31$ & 67 & 8.7 \\
\hline $20-30$ & 302 & 39.5 \\
\hline $11-19$ & 189 & 24.8 \\
\hline$\leq 10$ & 206 & 27.0 \\
\hline
\end{tabular}


Table 2 Otolaryngologists' attitudes towards nasopharyngeal fiberendoscopy (NFE) in children

\begin{tabular}{|c|c|c|c|}
\hline Parameter & Possible answers & No. of respondents & Perce \\
\hline Used to using NFE & & 576 & 75.4 \\
\hline \multicolumn{4}{|c|}{ Used to using alternative diagnostic tests } \\
\hline & Clinical evaluation & $175 / 269$ & 65.0 \\
\hline & Standardised questionnaires & $51 / 269$ & 19.0 \\
\hline & Posterior rhinoscopy & $34 / 269$ & 12.7 \\
\hline & Nasopharyngeal X-ray & $9 / 269$ & 3.3 \\
\hline \multicolumn{4}{|c|}{ Age of patients in whom NFE is considered feasible } \\
\hline & All pre-school years & 104 & 13.5 \\
\hline & $>3$ years & 235 & 30.8 \\
\hline & $3-8$ years & 425 & 55.7 \\
\hline
\end{tabular}

Indications for NFE

$\begin{array}{lll}\text { Nasal obstruction } & 33 & 4.3 \\ \text { Adenoidal facies } & 15 & 2.0 \\ \text { Recurrent or chronic middle ear disease } & 62 & 8.1 \\ \text { Rhinosinusitis } & 26 & 3.4 \\ \text { All of the above } & 628 & 82.2\end{array}$

Indications for in-patient NFE

$\begin{array}{lll}\text { Children with a genetic syndrome } & 42 & 5.5\end{array}$

$\begin{array}{lll}\text { Uncooperative children } & 65 & 8.5\end{array}$

$\begin{array}{lll}\text { Children aged }<18 \text { months in whom severe disease } & 84 & 11.0\end{array}$

is highly suspected

All of the above $\quad 283 \quad 37.0$

Children with genetic syndrome or aged $<18$ months $\quad 290 \quad 38.0$

Percentage of children in whom NFE is not considered feasible

in whom severe disease is highly suspected

$\begin{array}{lll}\leq 5 \% & 448 & 58.6 \\ 6-24 \% & 249 & 32.6 \\ 25-50 \% & 46 & 6.0 \\ 49-74 \% & 11 & 1.5 \\ \geq 75 \% & 10 & 1.3\end{array}$

Percentage of children experiencing untoward effects

$$
\begin{aligned}
& \leq 5 \% \\
& 6-25 \%
\end{aligned}
$$

Untoward effects

$\begin{array}{lll}\text { Nasal bleeding } & 579 & 75.8 \\ \text { Traumatic lesions } & 64 & 8.4 \\ \text { Syncope } & 90 & 11.8 \\ \text { Desaturation } & 21 & 2.7 \\ \text { Other } & 10 & 1.3\end{array}$


Table 2 Otolaryngologists' attitudes towards nasopharyngeal fiberendoscopy (NFE) in children (Continued)

\begin{tabular}{|c|c|c|c|}
\hline \multicolumn{4}{|l|}{ Tolerability } \\
\hline & None & 79 & 10.3 \\
\hline & Poor & 401 & 52.5 \\
\hline & Fair & 241 & 31.6 \\
\hline & Good & 37 & 4.9 \\
\hline & Excellent & 7 & $<1$ \\
\hline \multicolumn{4}{|c|}{ Final evaluation of NFE } \\
\hline & $\begin{array}{l}\text { A generally well-tolerated, minimally invasive } \\
\text { examination that can be used in most children; } \\
\text { very useful in clinical practice }\end{array}$ & 518 & 67.8 \\
\hline & $\begin{array}{l}\text { A not always well-tolerated, minimally invasive examination } \\
\text { that should only be used in the case of strong diagnostic } \\
\text { suspicion; moderately useful in clinical practice }\end{array}$ & 238 & 31.1 \\
\hline & $\begin{array}{l}\text { A poorly tolerated invasive examination that should only } \\
\text { be used in selected cases; not very useful in clinical practice }\end{array}$ & 8 & 1.1 \\
\hline
\end{tabular}

procedures to investigate adenoidal disease. About $65 \%$ chose a clinical evaluation (history of recurrent nasopharyngeal and/or middle ear infection and/or sleep disordered breathing, perceived nasal obstruction, speech hyponasality, and the proportion of oral breathing) as the elective alternative method. More than half said they used NFE only in children aged 3-8 years, and nearly $60 \%$ declared that they were able to complete the examination in more than $95 \%$ of children. NFE was considered safe by most of the respondents as $94 \%$ declared the occurrence of untoward effects (mainly nasal bleeding) in fewer than $5 \%$ of cases; however, more than $80 \%$ judged that it was poorly (about $52 \%$ ) or only fairly well tolerated (about $32 \%$ ). The majority had a positive opinion concerning the usefulness of NFE, and as many as $68 \%$ defined it "a generally well-tolerated, minimally invasive examination that can be used in most children; very useful in clinical practice".

Table 3 shows the methods of use. Almost all of the clinicians generally use flexible, small- diameter instruments, with the patient seated on a chair or a parent's lap. About $65 \%$ said they use gentle restraint (the method preferred by about $82 \%$ is to have the patient sitting on a parent's lap "with legs held between the thighs of the parent, who holds the child's wrists over the abdomen with one hand and the child's head against his or her chest with the other"). About one-third said that they did not use any topical drug before performing NFE, whereas $30 \%$ said they used local vasoconstrictors.

More than half declared that they graded adenoidal hypertrophy on the basis of the percentage of adenoidinduced choanal obstruction and the patency of the Eustachian tube, and fewer than $50 \%$ that they used a standardised grading system (mainly Cassano's [5], which was chosen by $36 \%$ of the respondents).
Table 4 shows the significant associations between the otolaryngologists' attitude towards the pediatric use of NFE and their demographic data. The use of NFE in clinical practice was apparently influenced by gender, age, and geographical working area because the most frequent users were male clinicians aged $<50$ years working in northern Italy. However, logistic multivariate analysis showed that only gender adjusted for geographical working area remained significantly associated with the routine use of NFE $(\mathrm{OR}=2.4, \mathrm{SE}=0.6,95 \% \mathrm{CI}=1.5-3.7 ; p<0.001$ for males).

Table 5 shows the significant associations between NFE methods and the demographic data. The choice of rigid endoscopes was only influenced by geographical working area as it was more frequent among the clinicians working in southern Italy (8.9 \% vs 3.4\%; $p=0.003)$. Grading adenoidal hypertrophy on the basis of the standardised classifications was influenced by both geographical working area and the working setting: it was more frequent among clinicians working in southern Italy $(54.6 \%$ vs $42.8 \% ; p=0.002)$ and those working in hospitals $(51.7 \%$ vs $42.1 \% ; p=0.050)$, although logistic multivariate analysis only confirmed the significance of geographical working area adjusted for working setting $(\mathrm{OR}=1.7, \mathrm{SE}=0.3 ; 95 \% \mathrm{CI}=1.1-2.5 ; p=0.006$ for clinicians working in southern Italy).

None of the other demographic variables was statistically associated with attitudes towards NFE or the way in which it was carried out.

\section{Discussion}

This is the first study specifically designed to evaluate Italian otolaryngologists' attitudes towards using NFE to diagnose children, and the way in which do so in routine clinical practice. The randomised selection of the 
Table 3 Otolaryngologists' methods of carrying out nasopharyngeal fiberendoscopy (NFE) in children

\begin{tabular}{|c|c|c|c|}
\hline Parameter & Possible answers & No. of otolaryngologists & Percer \\
\hline \multicolumn{4}{|c|}{ Recommended type of endoscope } \\
\hline & Flexible & 720 & 94.3 \\
\hline & Rigid & 44 & 5.7 \\
\hline \multicolumn{4}{|c|}{ Recommended endoscope diameter } \\
\hline & About $2 \mathrm{~mm}$ & 312 & 40.9 \\
\hline & About $3 \mathrm{~mm}$ & 369 & 48.3 \\
\hline & About $4 \mathrm{~mm}$ & 83 & 10.8 \\
\hline \multicolumn{4}{|c|}{ Recommended sterilisation } \\
\hline & Disposable sheaths & 574 & 75.2 \\
\hline & Disposable towels & 140 & 18.3 \\
\hline & Antiseptic solutions & 50 & 6.5 \\
\hline \multicolumn{4}{|c|}{$\begin{array}{l}\text { Use of endoscope connected to a video } \\
\text { recorder/monitor set }\end{array}$} \\
\hline & Yes & 588 & 76.9 \\
\hline & No & 176 & 23.1 \\
\hline
\end{tabular}

Method of removing nasal secretions before NFE

$\begin{array}{lll}\text { None } & 184 & 24.1 \\ \text { Urging child to blow his/her nose } & 211 & 27.6 \\ \text { Helping child to blow his/her nose } & 117 & 15.3 \\ \text { Nasal saline irrigation } & 44 & 5.7 \\ \text { Aspiration } & 208 & 27.3\end{array}$

Recommended position for NFE

Seated (alone or on parent's lap)

Need for restraint

Never

221

Only younger children

Always

Holding head gently

Sitting on a parent's lap ${ }^{a}$

Lying on back wrapped in a sheet

Only parents

Health workers, if parents unable to cooperate

$67 / 543$

28.9

64.8

6.3

Local pre-medication

None

Anesthetic

Lubricating ointment

Never
$341 / 543$

$443 / 543$

$33 / 543$

81.6

6.0

37.3

62.7

32.0

30.2

22.1

15.7

341 
Table 3 Otolaryngologists' methods of carrying out nasopharyngeal fiberendoscopy (NFE) in children (Continued)

First anatomical landmark assessed

$\begin{array}{lll}\text { Adenoids and nasopharynx } & 562 & 73.7 \\ \text { Ostiomeatal complex } & 200 & 26.3\end{array}$

Frequency of evaluation of anatomical structures other than adenoids during NFE

$\begin{array}{lll}\text { Never } & 10 & 1.3 \\ \text { Sometimes } & 348 & 45.5 \\ \text { Always } & 406 & 53.2\end{array}$

How adenoidal hypertrophy is graded

\begin{tabular}{lll} 
Percentage of choanal obstruction & 252 & 33.0 \\
$\begin{array}{l}\text { Percentage of choanal obstruction and } \\
\text { patency of Eustachian tube orifice }\end{array}$ & 417 & 54.5 \\
$\begin{array}{l}\text { Adenoidal hypertrophy: yes/no } \\
\text { Choanal obstruction: yes/no }\end{array}$ & 7 & 1.0 \\
\hline
\end{tabular}

Standardised classification for grading adenoidal hypertrophy

$$
\begin{aligned}
& \text { None } \\
& \text { Cassano's classification [5] } \\
& \text { Parikh's classification [9] } \\
& \text { Other }
\end{aligned}
$$

\section{7}

1.3

${ }^{a}$ with legs held between the thighs of the parent, who holds the child's wrists over the abdomen with one hand and the child's head against his or her chest with the other

participants and the very small number who failed to respond makes it unlikely that the only respondents were otolarygologists who used NFE. Consequently, it is reasonable to believe that the study population was truly representative of otolaryngologists working in Italy and the members of the two most important Italian otolaryngological associations. The high response rate may have been partially due to the fact that the questionnaire was presented during our most important national congresses.

Despite some differences related to age, gender and geography, the data indicate that the majority of the respondents use NFE in their pediatric clinical practice and have a generally positive attitude towards it because nearly $70 \%$ defined it as "a generally well-tolerated, minimally invasive examination that can be used in most children; very useful in clinical practice". As NFE has only recently been considered the preferred means of diagnosing adenoidal hypertrophy in children [5-7], it is not surprising that younger otolaryngologists use it more frequently than those aged $>50$ years.

It is worth noting that more than one-third of the respondents (mainly females aged $>50$ years) declared that they used alternative means of diagnosing adenoidal disease, including a clinical evaluation (65\%), standardised questionnaires (19\%), posterior rhinoscopy (about $13 \%$ ), and nasopharyngeal radiography (about $3 \%$ ). This is not surprising because, until recently, the many proposed methods of assessing adenoid size were not very accurate. In particular, the most widely used clinical scores aimed of predicting the severity of nasal obstruction $[9,10]$ is the nasal obstruction index (NOI), which is based on the proportion of oral breathing and speech hyponasality [10]. This was proposed by Paradise as a reliable and reasonably valid means of detecting the presence and degree of adenoidal hypertrophy in 1998 [10], but we have shown that it alone is less accurate than NFE in predicting the rate of adenoidal obstruction in children with perceived obstructed nasal breathing or recurrent/chronic middle ear disease, and should therefore be abandoned [7, 11].

About $3 \%$ of the responders said they used nasopharyngeal radiography as an alternative means of diagnosis, but it must be pointed out that its accuracy in assessing adenoidal hypertrophy (sensitivity $70 \%$ and specificity $52 \%$ ) is much less than that of NFE [12]. Furthermore, it has been found that radiological measurements such as adenoidal thickness (the distance along a perpendicular line from the basiocciput to the adenoid convexity) and the adenoid-nasopharyngeal ratio (the ratio between adenoid thickness and the distance between the basiocciput and the posterior edge of the hard palate) do not correlate with obstructive symptom scores $[8,13]$. 
Table 4 Otolaryngologists' attitudes towards nasopharyngeal fiberendoscopy (NFE) in children by demographic variables (only statistically significant relationships)

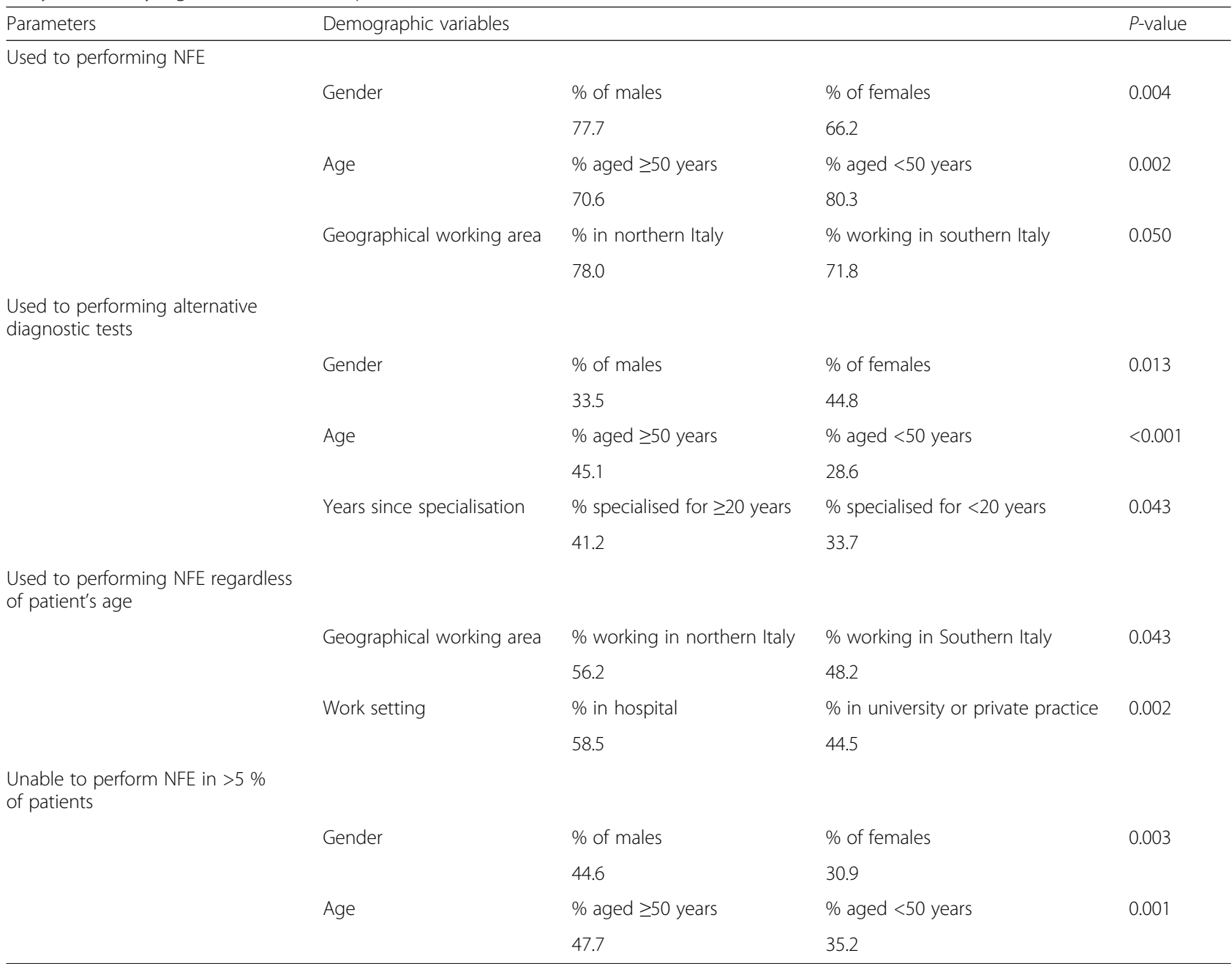

However, some clinicians still advocate the use of radiological assessments in children with suspected adenoidal disease $[2,4,14]$, especially in order to bridge the diagnostic gap in younger children who do not/cannot cooperate during an NFE examination [4]. Our findings indicate that there is some reluctance among Italian otolaryngologists to use NFE in small children, and most of them said that they only use it in older patients; only about $13 \%$ (mainly ENT specialists working in hospitals in northern Italy) said they use NFE regardless of age. Furthermore, nearly onethird of the respondents (males aged $>50$ years) stated that they cannot complete an NFE examination in up to $25 \%$ of patients. However, our experience [15] and that of others [3] indicates that NFE is feasible and tolerable in almost all children when it is carried out by a skilled otolaryngologist using a small-calibre flexible endoscope, and if every effort is made to find the best approach on the basis of the child's age.
NFE is generally considered safe: almost all of the respondents said that fewer than $5 \%$ of the procedures were associated with untoward side effects, mainly minor events such as nasal bleeding or traumatic lesions, and less frequently major events such as syncope (about $12 \%$ ) or desaturation (about $3 \%$ ). Thirty-eight percent excluded the possibility of using outpatient NFE in "children with a genetic syndrome" or "children aged $<18$ months in whom severe disease is highly suspected". To the best of our knowledge, no specific guidelines have yet been published but, on the basis of our experience [15] and that of Pagella [3], we consider that NFE can generally be used in an outpatient setting even in young non-syndromic children.

In terms of the way in which is NFE is carried out, the responses to most of the items varied widely. The only items indicating almost unanimous agreement concerned the recommended type of endoscope (flexible), 
Table 5 Methods of carrying out nasopharyngeal fiberendoscopy (NFE) in children by demographic variables (only statistically significant relationships)

\begin{tabular}{|c|c|c|c|c|}
\hline \multirow{2}{*}{$\begin{array}{l}\text { Parameter } \\
\text { Used to using rigid endoscopes }\end{array}$} & \multicolumn{3}{|l|}{ Demographic variables } & \multirow{2}{*}{$\frac{P \text {-value }}{0.003}$} \\
\hline & Geographical working area & $\%$ working in northern Italy & $\%$ working in southern Italy & \\
\hline & & 3.4 & 8.9 & \\
\hline \multirow{6}{*}{$\begin{array}{l}\text { Used to using endoscopes connected to a } \\
\text { video recorder/monitor set }\end{array}$} & Gender & $\%$ of males & $\%$ of females & 0.009 \\
\hline & & 78.5 & 68.0 & \\
\hline & Age & $\%$ aged $\geq 50$ years & $\%$ aged $<50$ years & 0.029 \\
\hline & & 80.4 & 73.5 & \\
\hline & Years since graduation & $\%$ graduated $\geq 30$ years ago & $\%$ graduated $<30$ years ago & 0.035 \\
\hline & & 80.0 & 73.2 & \\
\hline \multirow[t]{2}{*}{ Used to using NFE bilaterally } & Geographical working area & $\%$ working in northern Italy & $\%$ working in southern Italy & 0.012 \\
\hline & & 40.1 & 49.8 & \\
\hline \multirow{4}{*}{$\begin{array}{l}\text { Used to using standardised classification to } \\
\text { grade adenoidal hypertrophy }\end{array}$} & Geographical working area & $\%$ working in northern Italy & $\%$ working in southern Italy & 0.002 \\
\hline & & 42.8 & 54.6 & \\
\hline & Work setting & $\%$ in hospital & $\%$ in university or private practice & 0.050 \\
\hline & & 51.7 & 42.1 & \\
\hline \multirow{10}{*}{$\begin{array}{l}\text { Used to grading adenoidal hypertrophy } \\
\text { according to Cassano's classification [5] }\end{array}$} & Gender & $\%$ of males & $\%$ of females & 0.047 \\
\hline & & 25.2 & 39.3 & \\
\hline & Age & $\%$ aged $\geq 50$ years & $\%$ aged $<50$ years & $<0.001$ \\
\hline & & 17.5 & 35.4 & \\
\hline & Years since graduation & $\%$ graduated $\geq 30$ years ago & $\%$ graduated $<30$ years ago & 0.001 \\
\hline & & 19.5 & 35.5 & \\
\hline & Years since specialisation & $\%$ specialised for $\geq 20$ years & $\%$ specialised for $<20$ years & 0.024 \\
\hline & & 20.3 & 31.6 & \\
\hline & Geographical working area & $\%$ working in northern Italy & $\%$ working in southern Italy & 0.001 \\
\hline & & 34.3 & 18.1 & \\
\hline
\end{tabular}

the position of the patient during NFE (sitting alone or on a parent's lap), and restraint (with the parent blocking the movement of the child sitting on his/her lap). Various means of carrying out NFE examinations have been proposed [3, 4, 16-19], but our own experience confirms that the methods indicated by the answers of our respondents are effective and welltolerated by almost all children [15]. Some authors [18-21] advocate the use of a rigid nasal endoscope, but this may be less well tolerated as it is associated with a failure rate of up to $12 \%$ of children undergoing endoscopy in a supine position even after the administration of topical nasal anesthetics and decongestants [18, 19].

Only $32 \%$ of our respondents said that they do not administer any topical drugs before an NFE examination, whereas the others pre-medicate the nasal cavities with local vasoconstrictors (30\%), an anesthetic (22\%), or lubricating ointment (about $16 \%$ ). We have previously reported that NFE can be successfully carried out in most patients without the aid of any of these [15] and, given that the use of topical decongestants has been proscribed by the Italian Medicines Agency in children aged $<12$ years [22], we suggest they should they not be used.

There was also considerable heterogeneity in the way that adenoidal hypertrophy is graded: just over half of the respondents base the grading on the percentage of choanal obstruction and the possible impaired patency of the Eustachian tube orifice, whereas about one-third only use the former. Only about $48 \%$ said they used a standardised classification (mainly that of Cassano [5]), most of whom work in hospitals in southern Italy. This suggests the need for educational programmes supported by national otolaryngological societies aimed at promoting the use of standardised systems of scoring adenoidal hypertrophy in order to make medical reports comparable. 


\section{Conclusions}

The findings of this study seem to indicate that Italian otolaryngologists use NFE, and are quite confident about its effectiveness and safety in routine pediatric practice. However, there is some reluctance to using it in younger children, and no unanimous agreement about how it should be carried out. This lack of a standardised approach may account for failures in some patients, and encourage resort to alternative means of diagnosis that should actually be abandoned.

Given the medical advantages of NFE, it is essential to clarify the many still controversial aspects of the procedure by means of comparative studies and educational programmes supported by national health authorities.

\section{Competing interest}

The authors declare that they have no conflict of interest.

\section{Authors' contribution}

ST conceived the study, partecipated in its design and coordination, peformed statystical analysis and draft the manuscript; LP partecipated in study design and coordination, gave important contributions to data interpretation; PM, GS and PC partecpated in study coordination and helped to draw the manuscript. All the authors gave their final approval to the manuscript.

\section{Acknowledgements}

This study was supported by the Italian Society of Otolaryngology and Head and Neck Surgery (SIOeChCF), and the Italian Society of Pediatric Otolaryngology (SIOP).

\section{Financial support disclosure}

This study was not supported by funding from any extramural sources.

\section{Author details}

${ }^{1}$ Otolaryngology Unit, Department of Clinical Sciences and Community Health, University of Milan, Fondazione IRCCS Ca' Granda Ospedale Maggiore Policlinico, Via F. Sforza 35, 20122 Milan, Italy. ${ }^{2}$ Pediatric Highly Intensive Care Unit, Department of Pathophysiology and Transplantation, University of Milan, Fondazione IRCCS Ca' Granda Ospedale Maggiore Policlinico, Milan, Italy. ${ }^{3}$ Academic Oncologic Department, Otolaryngology Service, University of Turin, San Luigi Gonzaga Hospital, Orbassano, Turin, Italy.

Received: 14 December 2015 Accepted: 23 February 2016

\section{1.}

\section{References}

1. Marseglia GL, Caimmi D, Pagella F, et al. Adenoids during childhood: the facts. Int J Immunopathol Pharmacol. 2011;24:1-5.

2. Bitar MA, Birjawi G, Youssef $M$, et al. How frequent is adenoid obstruction? Impact on the diagnostic approach. Pediatr Int. 2009;51:478-83.

3. Pagella F, Pusateri A, Chu F, et al. Adenoid assessment in paediatric patients: the role of flexible nasal endoscopy. Int J Immunopathol Pharmacol. 2011;24:49-54

4. Lertsburapa K, Schroeder Jr JW, Sullivan C. Assessment of adenoid size: A comparison of lateral radiographic measurements, radiologist assessment, and nasal endoscopy. Int J Pediatr Otorhinolaryngol. 2010;74:1281-5.

5. Cassano P, Gelardi M, Cassano M, et al. Adenoid tissue rhinopharyngeal obstruction grading based on fiberendoscopic findings: a novel approach to therapeutic management. Int J Pediatr Otorhinolaryngol. 2003;67:1303-9.

6. Marchisio P, Torretta S, Capaccio P, et al. Clinical assessment of adenoidal obstruction based on the nasal obstruction index is no longer useful in children. Otolaryngol Head Neck Surg. 2010;142:237-41.

7. Torretta S, Marchisio P, Esposito S, et al. Diagnostic accuracy of the nasal obstruction index in detecting adenoid hypertrophy in children without allergy. Int J Pediatr Otorhinolaryngol. 2011;75:57-61.

8. Mlynarek A, Tewfik MA, Hagr A, et al. Lateral neck radiography versus direct video rhinoscopy in assessing adenoid size. J Otolaryngol. 2004;33:360-5.
9. Bitar MA, Rahi A, Khalifeh M, et al. A suggested clinical score to predict the severity of adenoid obstruction in children. Eur Arch Otorhinolaryngol. 2006; 263:924-8.

10. Paradise JL, Bernard BS, Colborn DK, et al. Assessment of adenoidal obstruction in children: clinical signs versus roentgenographic findings. Pediatrics. 1998;101:979-86.

11. Marchisio P, Torretta S, Capaccio P, et al. Clinical assessment of adenoidal obstruction based on the nasalobstruction index is no longer useful in children. Otolaryngol Head Neck Surg. 2010;142:237-41.

12. Ysunza A, Pamplona MC, Ortega JM, et al. Videofluoroscopic evaluation of adenoidal hypertrophy and velopharyngeal closure during speech. Gac Med Mex. 2011;147:104-10.

13. Feres MFN, Hermann JS, Cappellette M, et al. Lateral X-ray view of the skull for the diagnosis of adenoid hypertrophy: a systematic review. Int J Pediatr Otorhinolaryngol. 2011;75:1-11.

14. Caylakli F, Hizal E, Yilmaz I, et al. Correlation between adenoid-nasopharynx ratio and endoscopic examination of adenoid hypertrophy: a blind, prospective clinical study. Int J Pediatr Otorhinolaryngol. 2009;73:1532-5.

15. Torretta S, Marchisio P, Cappadona M, et al. Nasopharyngeal fiberendoscopy in children: a diagnostic challenge in current clinical practice: how we do it. Int J Pediatr Otorhinolaryngol. 2013;77:747-51.

16. Kindermann CA, Roithmann R, Lubianca Neto JF. Sensitivity and specificity of nasal flexible fiberoptic endoscopy in the diagnosis of adenoid hypertrophy in children. Int J Pediatr Otorhinolaryngol. 2008;72:63-7.

17. Kubba H, Bingham BJ. Endoscopy in the assessment of children with nasal obstruction. J Laryngol Otol. 2001;115:380-4.

18. Ameli F, Castelnuovo P, Pagella F, et al. Nasal endoscopy in asthmatic children: clinical role in the diagnosis of rhinosinusitis. Rhinolog. 2004;42:15-8.

19. Tosca MA, Riccio AM, Marseglia GL, et al. Nasal endoscopy in asthmatic children: assessment of rhinosinusitis and adenoiditis incidence, correlations with cytology and microbiology. Clin Exp Allergy. 2001;31:609-65.

20. Yilmaz I, Caylakli F, Yilmazer C, et al. Correlation of diagnostic systems with adenoidal tissue volume: a blind prospective study. Int J Pediatr Otorhinolaryngol. 2008;72:1235-40.

21. Kubba H, Bingham BJ. Endoscopy in the assessment of children with nasal obstruction. J Laryngol Otol. 2001;115:380-4.

22. Agenzia Italiana del Farmaco. Decongestionanti nasali nei bambini: i rischi superano i benefici. Bollettino d'Informazione sui Farmaci 2007-estratto anticipato; 2:1-8. www.agenziafarmaco.it

Submit your next manuscript to BioMed Central and we will help you at every step:

- We accept pre-submission inquiries

- Our selector tool helps you to find the most relevant journal

- We provide round the clock customer support

- Convenient online submission

- Thorough peer review

- Inclusion in PubMed and all major indexing services

- Maximum visibility for your research

Submit your manuscript at www.biomedcentral.com/submit
) Biomed Central 